\title{
Application of resistance spot welding in car body production
}

\author{
Emil Spišák, Luboš Kašcák, Ján Viňáš*
}

Institute of Technology and Management, Faculty of Mechanical Engineering, Technical University of Košice, Mäsiarska 74, 04001 Košice, Slovakia

\begin{abstract}
The paper deals with the optimization of parameters of resistance spot welding and quality analysis of welded joints made of combination of galvanized steel sheets TRIP RAK 40/70+Z100MBO and DX51D + Z (EN 10142/2000). It is an advanced material combination frequently used in designing car body parts. The welded joints with various welding parameters were prepared. The quality of welded joints was evaluated by non-destructive and destructive tests. For evaluation of joints quality the shear tension test on spot joints according to STN 05 1122 standard was used. Some samples were prepared for metallographic analysis where the influence of the welding parameters on the structure of welded joint was observed. The influence of welding parameters on the dimensions of the weld nugget, and the occurrence of pores in the weld metal caused by evaporation of zinc from the coating were observed as well. Hardness was evaluated on metallographic scratch patterns according to STN EN ISO 14271 standard.
\end{abstract}

Keywords: Resistance spot welding; carrying capacity; metallography; microhardness.

\section{Introduction}

Resistance spot welding (RSW) is one of the oldest of the electric welding processes in use by industry today. The weld is made by a combination of heat, pressure and time. RSW has been widely employed in sheet metal fabrication for several decades because it is a simple and cost-effective joining method. It is the predominant welding technique used in automotive industry due to its high efficiency in manufacturing thin metal sheets. A wide variety of metal sheets up to $3 \mathrm{~mm}$ thickness can be handled by the resistance spot welding method [1,2]. In the last decade a change in body shell mass production has occurred in the automotive industry. In answer to the intensifying energy crisis and in order to meet customer requirements for automobiles such as weight reduction for energy saving and enhancement of passenger safety [3].

One of the possibilities of decreasing the car weight and consequently lowering the fuel consumption is using various combinations of materials, such as combination of conventional deep-drawn steel sheet and high-strength steel sheet. In the areas, where high passive safety is needed, high-strength steels such as TRIP and DP steels can be used. The usage of such steels can significantly reduce the car weight. Their strength properties allow reducing the thicknesses of particular segments of a car body $[4,11]$. As a result, there has been a recent focus on the weldability of these steels. Wide range of various steel sheets used in car body production are shown in Figure 1.

Since the RSW process is the primary joining method used in automotive production, a detailed understanding of metallurgical changes and their effects 
on the mechanical performance of AHSS welds is required for safe integration into the automotive architecture $[5,12]$.

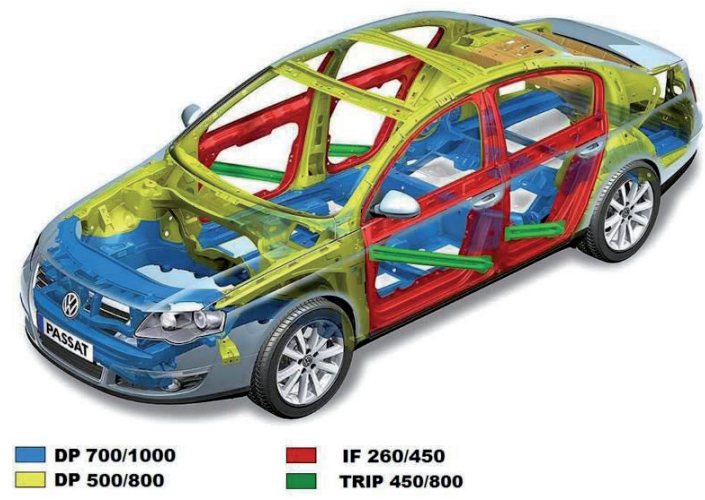

Fig. 1: Steels used in car body production (Yield Strength/Tensile Strength), VW Passat [6].

The type of welding regime influence on the quality of spot welds, as was described in $[1,2,4]$. Temperature processes during resistance spot welding can be described (under certain simplified condition) by an equation, based on the differential equation of heat conduction with the heat source:

$$
C \gamma \frac{\delta T}{\delta t}=\Delta(\lambda \Delta T)+\rho i^{2}(x, y, z, t)
$$

where: $\mathrm{T}$ - temperature (temperature difference T-T0 [deg], t - time [s], C - specific heat [J.g $\left.{ }^{-1} . \mathrm{deg}^{-1}\right]$, $\gamma$ - specific density $\left[\mathrm{g} . \mathrm{cm}^{-3}\right], \lambda$ - heat conductivity $\left[\mathrm{W} \cdot \mathrm{cm}^{-1} \cdot \mathrm{s}^{-1} \cdot \mathrm{deg}^{-1}\right], \rho$-specific resistance $\left[\Omega \cdot \mathrm{mm}^{2} \cdot \mathrm{m}^{-1}\right]$, $\mathrm{i}$ - density of welding current $\left[\mathrm{A} \cdot \mathrm{cm}^{-2}\right]$ as a function of place and time, $\Delta$ - Hamilton operator

\section{Analysis of Weldability}

DX51D material is a low carbon steel with good weldability. Its carbon content is up to $0.12 \%$. The maximum recommended content of carbon for resistance spot welding is $0.3 \%[1,2]$.

TRIP steels are characterized by high strength (approximately $1000 \mathrm{MPa}$ ) and good plastic properties (A5 about 20\%). The high strength is achieved by non-steady structures such as martensite and bainite. Good plastic properties are achieved by soft ferritic matrix.

TRIP steels are of good weldability. However, due to their multi-phase structure, the influence of welding on the changes of particular phases in the material is to be taken into account. Conventional TRIP steels are conceived on the base of C-Mn-Si. However, modification of the steels, with replacing Si by Aluminium, has a positive influence on their weldability, without any negative influence on the TRIP effect of the steel. Besides these elements, in low-alloy TRIP steel applied in automotive production there are also elements like $\mathrm{Cu}$, $\mathrm{Cr}, \mathrm{Nb}, \mathrm{Ni}$ a. O., which influence the stability of particular phases and the height of transformation temperatures.

The phase transformations occur during welding in the area of the weld of the TRIP steel, which are mainly caused by the heat. Some transformations are caused by compressive force of the welding electrodes as well.

Heating causes austenization of the weld metal. Heating above the critical temperature (above $\mathrm{A}_{c 3}$ ) causes transformation of the initial ferritecementite structure to austenitic structure with the change of lattice $\mathrm{Fe} \alpha(\mathrm{C}) \rightarrow \mathrm{Fe} \gamma(\mathrm{C})$ and changes in the atoms arrangement [7]. Further transformation during welding is the bainitic transformation which occurs in temperatures $500^{\circ} \mathrm{C}$, higher than the temperature of the start of martensite transformation. Bainitic transformation is partially diffusive and partially diffusionless. Transformation $\mathrm{Fe} \alpha(\mathrm{C}) \rightarrow \mathrm{Fe} \gamma(\mathrm{C})$ is carried out by so-called shear (diffusionless) mechanism, whereas the changes in carbon distribution are caused by diffusion. A characteristic sign of the bainitic transformation is the amount of non-transformed, so-called retained austenite.

In the weld metal, the martensitic (diffusionless) transformation occurs. Martensitic crystals are formed by a shear mechanism. Lamellar formations grow from nuclei - crystal-lattice defects of austenite. Movement of atoms in the lattice is shorter than the distance of adjacent atoms. Due to different specific volumes of austenite and martensite, the elastic deformation in the coherent area increases which causes so-called interphase boundary. In the structure there is some retained austenite and surrounding laths of martensite prevent it from transforming [7-10].

\section{Materials and Experiments}

Double-sided hot-dip galvanized steel sheets TRIP RAK 40/70+Z100MBO of $0.77 \mathrm{~mm}$ thickness made by Voestalpine Austria and DX51D + Z (EN 
Table 1: Chemical composition of used steel sheets (in [\%] of wt).

\begin{tabular}{|c|c|c|c|c|c|c|c|c|}
\hline Material & c & Mn & Si & $\mathbf{P}$ & s & Al & Cu & $\mathrm{Ni}$ \\
\hline RAK 40/70 & 0.141 & 1.627 & 0.185 & 0.046 & 0.002 & 1.986 & 0.053 & 0.016 \\
\hline $\mathrm{DX51D}+Z$ & 0.064 & 0.178 & 0.007 & 0.016 & 0.002 & 0.120 & 0.041 & 0.002 \\
\hline Material & Cr & ii & v & $\mathrm{Nb}$ & Mo & Co & & \\
\hline RAK 40/70 & 0.056 & 0.007 & 0.017 & 0.037 & 0.024 & 0.047 & & \\
\hline DX51D+Z & 0.023 & 0.002 & 0.005 & 0.015 & 0.004 & 0.019 & & \\
\hline
\end{tabular}

Table 2: Basic mechanical properties of used steel sheets

\begin{tabular}{|l|l|l|l|}
\hline Material & Yield Strength [MPa] & Tensile Strength [MPa] & Elongation [\%] \\
\hline RAK 40/70 & 450 & 766 & 26 \\
\hline DX51D+Z & $\geq 140$ & $270-500$ & 23 \\
\hline
\end{tabular}

10142/2000) of $1 \mathrm{~mm}$ thickness made by U.S.Steel Košice, Ltd. were used for the experiments. The chemical composition of the observed materials and their basic mechanical properties are shown in Table 1 and Table 2.

Average thicknesses of zinc coatings measured by contact thickness gauge Quanix were:

RAK 40/70+Z100MBO - $18.2 \mu \mathrm{m}$

DX51D + Z (EN 10142/2000) - $16.8 \mu \mathrm{m}$.

Resistance spot welding was carried out on a pneumatic spot welding machine BPK 20 made by VTS ELEKTRO Bratislava. CuCr welding electrodes according to ON 423039.71 standard were used. The diameter of working area of the electrode was $\mathrm{d}=5 \mathrm{~mm}$. The used parameters of resistance spot welding including pressing force of electrodes $\mathrm{Fz}=6 \mathrm{kN}$, welding time $\mathrm{T}=20$ periods and welding currents I of 5.5 (sample A), 6.0 (sample B), 6.5 (sample C) and 7.0 (sample D) kA. The welding parameters were determined according to the recommended welding parameters by IIW International Institute of Welding, adapted to our welding machine and its possibilities.

The quality of the spot welds was evaluated by following tests: tensile test, microhardnesses test and a metallographical analysis. The samples with dimensions of $40 \times 90 \mathrm{~mm}$ and with $30 \mathrm{~mm}$ of lapping according to STN 051122 standard were used for the experiments. The surfaces of the samples were degreased in concentrated $\mathrm{CH} 3 \mathrm{COCH}$. The tensile test was carried out on the metal strength testing machine TIRAtest 2300 with the loading speed of $8 \mathrm{~mm} / \mathrm{min}$. Metallographical analysis was realized on the scratch patterns prepared according to ISO 6507-1 and ISO 6507-
2 standards and microhardnesses analysis was realized according to STN EN ISO 14271 standard with the applied load of $980 \mathrm{mN}$ in the range of 10 $-15 s$.

\section{Tensile test}

\section{Results and Discussion}

The tensile test showed, that only fusion welded joints occurs in all observed welding parameters. The values of carrying capacities Fmax of welded joints ranged from $6166 \mathrm{~N}$ to $7680 \mathrm{~N}$. Measured values of carrying capacities of spot welded joints Fmax [N] on welding current I [kA] are shown in Figure 2. The highest values of carrying capacity were measured on samples prepared with welding current $I=6.0 \mathrm{kA}$. Further increasing of the welding current caused decreasing of carrying capacity of the resistance spot welds.

Dependency of carrying capacity of spot welds Fmax on welding current I can be expressed:

$$
F_{\text {max }}=-1666.7 I^{2}+20657 I-56449
$$

with coefficient of determination $\mathrm{R}^{2}=0.88$

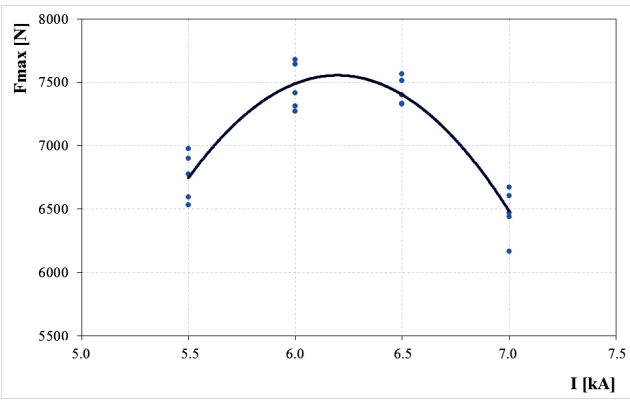

Fig. 2: Dependency of carrying capacities Fmax [N] on welding current I [kA]. 
The tensile tests were executed under displacement control conditions on the specimen configurations in order to characterize the static behavior of the joints. The maximum shearing load was the most significant value obtained from the load-displacement curves - Figure 3. The form of the curves indicates the behavior of the spot welded joints under load as well as the capacity for deformation. All the curves have the similar form besides the curve of sample made with welding current of $\mathrm{I}=6.0 \mathrm{kA}$.

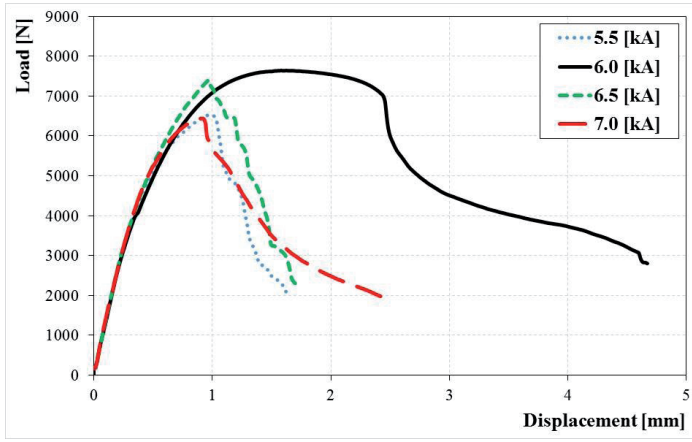

Fig. 3: Load-displacement curves of spot welds from tensile test.

\section{Metallographical analysis}

The base material of DX51D $+Z$ with a fine-grained ferrite-perlite structure as shown in Figure $4 a$.

The average grain size in the structure is G7, measured according to standard STN EN ISO 643.
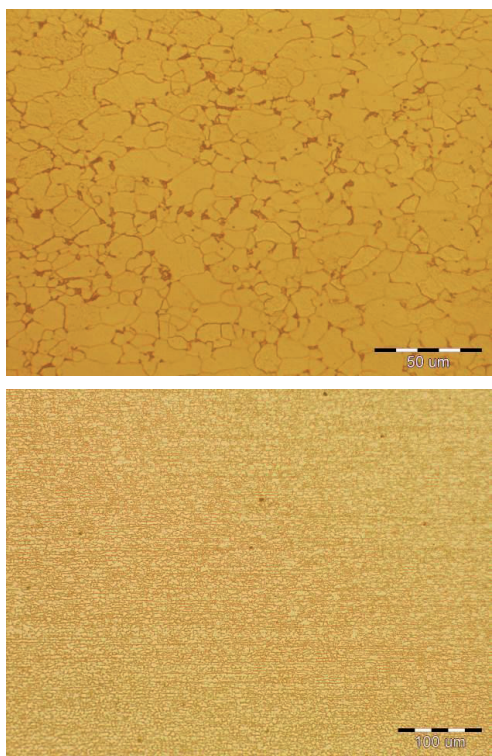

Fig. 4: Microstructure of base material a) DX51D + Z, b) RAK 40/70
The microstructure of the TRIP steel base material is shown in Figure 4b. It is a fine-grained multiphase structure with dominant ferrite component, bainite and retained austenite segregated on boundaries of ferrite grains. The average grain size in the structure is G9 according to above mentioned standard.

The metallographical analysis confirmed formation of fusion welded joints with characteristic areas of weld metal (WM), heat affected zone (HAZ) and base material (BM). Figure 5 shows the macrostructure of a spot weld of the sample welded with parameters $\mathrm{A}$. When using the lowest value of welding current, the weld joints were of high quality, fusible and without any defects, but the weld nugget had smaller dimensions, which is in accordance with the values of their carrying capacity.

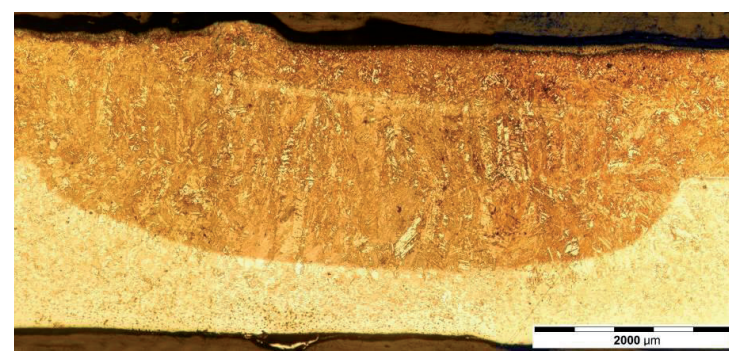

Fig.5: Microstructure of welded joint of A sample.

The macrostructures of a weld joint show the solidification process of weld metal with a characteristic dendrite structure typical for resistance spot welds. The microscopic observation of macrostructures of the welds shows no pores and cavities occurring in the weld metal. In the HAZ from the side of DX51D steel a non-uniform microstructure with polyedric ferrite was observed. Microstructure of weld metal with the part of DX51D steel is shown in Figure 6a. It is a coarsegrain structure with bainite and acicular ferrite. Microstructure of weld metal with tempered martensite of RAK steel is shown in Figure 6b.

The microstructure of sample $B$ is shown in Figure7. In comparison with sample A, the weld nugget of bigger size was observed. The diameter of weld nugget correspond with the diameter of welding tips that lead to increasing of carrying capacity of samples B. No cracks occurred in weld metal and heat affected zone of these samples.

The microstructure of DX51D $+Z$ can be 
characterized as a fine-grained ferrite-perlite structure. Because of heating in resistance spot welding, continual growth of grains towards the weld metal can be observed. A significant growth of perlite grains occurs in the heat affected zone. On the boundary of the heat affected zone and the weld metal, there is bainite transformation of perlite grains (Figure 8).
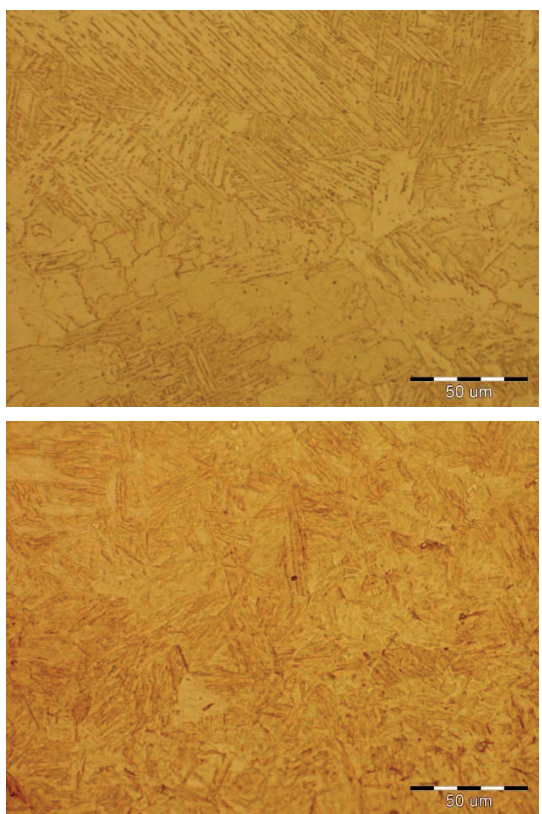

Fig. 6: Microstructure of weld metal of a) DX51D, b) RAK 40/70.

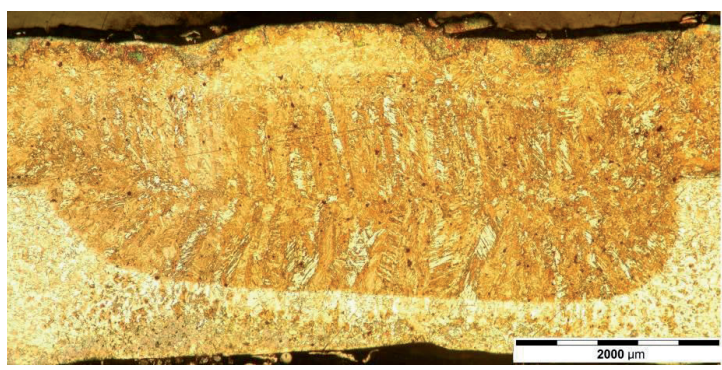

Fig. 7: Microstructure of welded joint of B sample,

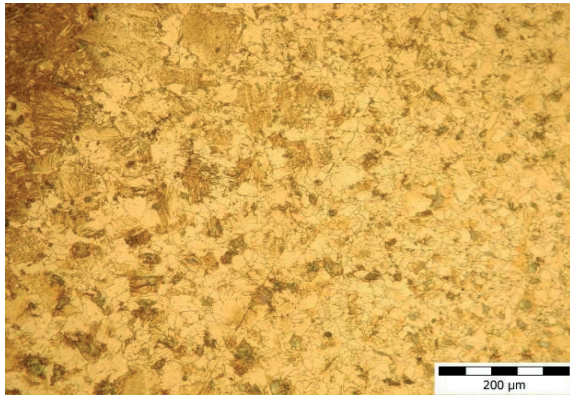

Fig. 8: Heat affected zone of DX51D + Z steel.

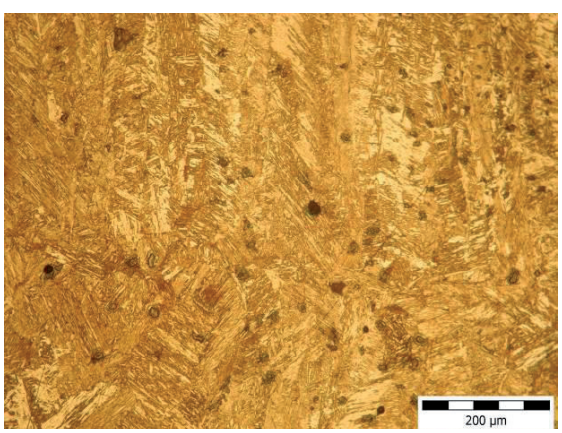

Fig. 9: Weld metal of TRIP steel.

Figure 9 shows microstructure of weld metal of a B sample in the part of TRIP steel. The microstructure of weld metal consists of mostly fine-grained martensite arranged in typical lamellar formations. Such lamellar formations prevent the austenite from transformation; therefore the retained austenite occurs in the structure. Besides martensite, also ferrite and both forms of bainite occured in the microstructure of weld metal. The formed carbide inclusions was also observed in the weld metal.

In the part of the weld metal of DX51D + Z (Figure 10) of sample $C$, a bainite-ferrite microstructure can be observed. There are dispersed ferrite grains on the boundaries of bainite grains. In the part of the weld joint of DX51D $+Z$, the structure of good visible dendrites is the same as in the part of the weld nugget of TRIP steel, characteristic for solidification processes of the weld metal in resistance spot welding.

When using welding current 7 kA (sample D), the cracking occurred in heat affected zone of TRIP steel, as shown in Figure 11.

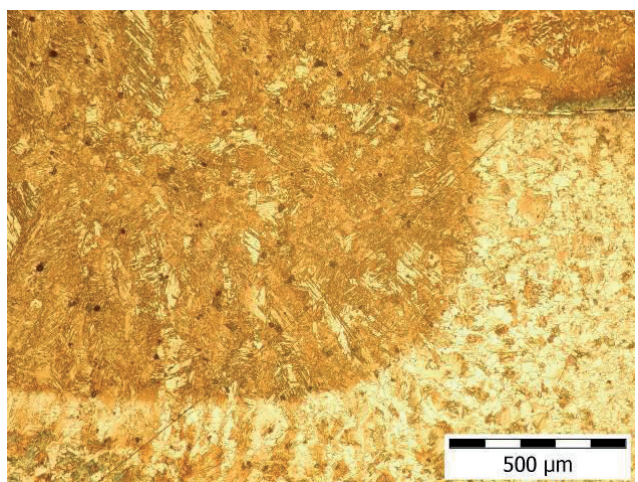

Fig. 10: Boundary of weld metal and heat affected zone of DX51D $+Z$, sample C. 


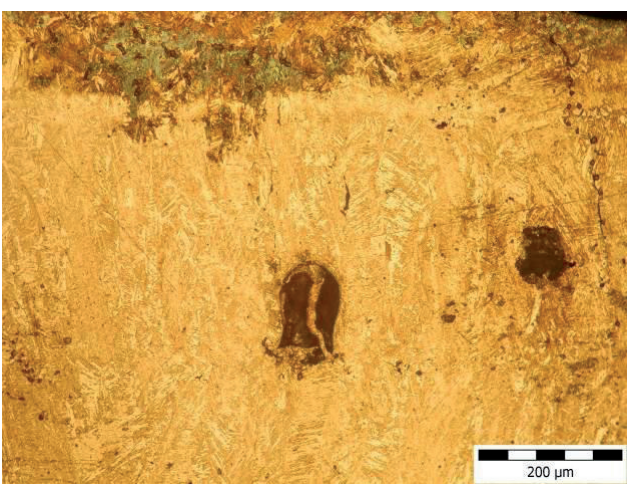

Fig. 11: Detail of cavities and cracks in weld nugget and heat affected zone in sample D.

Current intensity had a significant influence on the height of the weld nugget. The character of cracks is intercrystalline. The amount of the heat and martensitic structure or transformation process of particular compounds of the structure during welding was the cause of their creation. However, a dynamic process of welding with a hard regime was used, the creation of cracks occurred when using welding current over $6.5 \mathrm{kA}$. These cracks caused significant decreasing of carrying capacity of the spot welds. Therefore welding current $\mid=$ $7.0 \mathrm{kA}$ is not suitable for welding the observed combination of materials.

Such cracks occur only in heat affected zone of TRIP steel. Evaporation of $\mathrm{Zn}$ coating from the sheet surfaces under welding tips was observed in all samples.

\section{Microhardness}

On the basis of the realized measurements it can be stated, that the change of used parameters of resistance spot welding did not have a significant influence on the microhardness changes in the weld metal, or heat affected zone, as shown in Figure 12.

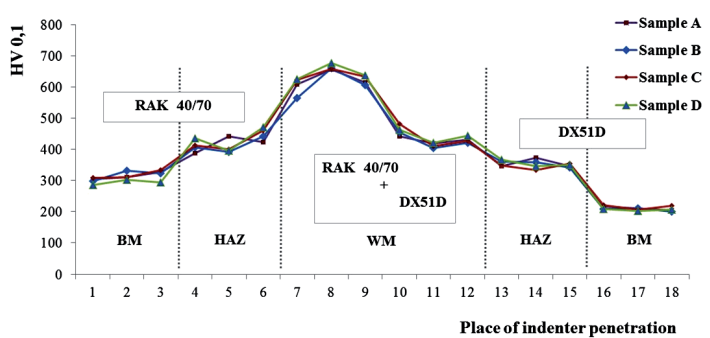

Fig. 12: Microhardness values of all observed samples.
The measured values of microhardness are in accordance with the observed microstructures. The measured value of microhardness of TRIP steel was 677 HV 0.1. This value of microhardness corresponds with the microhardness of a dominant martensitic compound of the weld metal. The maximum value of microhardness of DX51D $+Z$ steel was $463 \mathrm{HV}$ 0.1. This value is in accordance with the bainite structure of the weld metal. The change of microhardness in the weld nugget was continuous and it corresponded to mixing the weld metal of particular types of steel.

\section{Conclusion}

Application of high-strength steels in order to reduce the weight of car bodies is increasingly important in designing new cars. Nowadays, the DP steels amount to more than $75 \%$ of a car body and the portion of TRIP steels in production of safety elements is approximately $5 \%$ of the steel sheets.

On the basis of the realized experiment, the following conclusions can be formed:

$\checkmark$ Fusion weld joints occurred with all used parameters of resistance spot welding, even if the lowest welding current of $5.5 \mathrm{kA}$ was used.

$\checkmark$ The highest values of tensile strength were observed in the samples made with welding current $I=6.0 \mathrm{kA}$ and the lowest values of carrying capacity were observed in samples made with welding current $\mathrm{I}=7 \mathrm{kA}$.

$\checkmark$ Increasing the parameters of the welding current above the value of $6.0 \mathrm{kA}$ proved ineffective, because the carrying capacity of samples decreased, and overheating of the weld metal and expansion of the heat affected zone occurred, which proved to be a critical area in the welding.

$\checkmark$ The metallographical analysis confirms that the chosen combination of deep-drawn sheet $D X 51 D+Z$ and high-strength sheet TRIP RAK $40 / 70+Z 100 M B O$ is suitable for resistance spot welding. On the basis of the results it can be stated, that welding current has a determining influence on the weld joint. Weld joints of high quality were made with welding currents of $6.0 \mathrm{kA}$ and $6.5 \mathrm{kA}$.

$\checkmark$ When using the welding current of $5.5 \mathrm{kA}$, weld joint was of high quality, fusible and without defects, but the weld nugget had smaller dimensions in comparison with weld nuggets made under parameters of $I=6.0 \mathrm{kA}$ and $I=6.5 \mathrm{kA}$. 
$\checkmark$ The metallographical analysis confirmed that the welding current of $7.0 \mathrm{kA}$ is not suitable for the examined thickness and sheet combination due to cracking in the heat affected zone of multi-phase material of TRIP 40/70+Z100MBO.

The resistance spot welding is the suitable method for joining the evaluated combination of materials of car body parts. The main problems occurred in the area between base material and heat affected zone. Substantial optimization of the welding process can prevent welds from cracking, especially in ultra-high-strength TRIP steels. The development of multi-phase TRIP steels for automotive industry leads to development of bainiteferritic structure with retained austenite parts.

\section{Acknowledgments}

Authors are grateful for the support of experimental works by project APVV-0682-11: "Application of progressive tool coatings for increasing the effectiveness and productivity of forming sheets made of modern materials" and project VEGA 1/0872/14 "Research and optimization of drawability and joinability evaluation of highstrength steel sheets and aluminium sheets".

\section{References}

[1] Zhang, H., Senkara, J. (2006). Resistance Welding: Fundamentals and Applications. Taylor\&Francis Group, New York.

[2] Lipa, M., (1995). Resistance welding. Weldtech, Bratislava. (in Slovak)

[3] Mukhopadhyay, G., Bhattacharya, S., Ray, K.K. (2009). Effect of pre-strain on the strength of spot-welds. Materials and Design, Vol. 30, pp. 2345-2354

[4] SPIŠÁK, E. et al. (2011). Mechanical technology. Faculty of Mechanical Engineering, Košice. (in Slovak)

[5] Khan, M. I., Kuntz, M. L., Biro, E., Zhou, Y. (2008). Microstructure and Mechanical Properties of Resistance Spot Welded Advanced High Strength Steels. Materials Transactions, Vol. 49, No. 7, pp. 1629-1637

[6] http://www.stahl-info.de/images/Automobil_Leicht_und_ sicher_PassatSicherheitsstruktur_64934.jpg (10.8.2010)

[7] Janota, M. (1975). type of welding regime in resistance welding. Welding - Zváranie, p. 259-261. (in Slovak)

[8] Puškár, A., Michel', J., Pulc, V. (1998). Materials Science I. University of Žilina, Žilina. (in Slovak)

[9] Cretteur, L., Koruk, A. I., Tosal-Martinez, L. (2002). Improvement of weldability of TRIP Steels by use of in-situ pre- and post-heat treatments, Int. Conf. On TRIP, Ghent, pp. 353-358.

[10] Bleck, W. (2002). Using the TRIP effect - the dawn of a promising of cold formable steels. Int. Conf. On TRIP - Aided High Strenght Ferrous Alloys, pp. 13-23.
[11] Spišák,E., Kaščák, L’., Joining car body steel sheets using the clinching method. In: Acta Mechanica Slovaca. Volume. 15, No. 1 (2011), p. 28-34. - ISSN 1335-2393

[12] Spišák,E., Kaščák, L., Mechanical Joining of Steel Sheets in Automotive Industry. In: Acta Mechanica Slovaca. Volume 18, No. 3-4, (2014), p. 6-12. - ISSN 1335-2393

\section{Biographical notes}

Emil Spišák, prof. Ing. CSc., (born in 1955) is a professor at the Institute of Technologies and Management, Faculty of Mechanical Engineering, Technical University of Košice. He graduated from the Faculty of Mechanical engineering in 1980. He is the Head of the Department of Mechanical Engineering Technologies and Materials and Vice-Rector for Development and Construction of the University. Professor Spišák is the national secretary and a member of International Deep-Drawing Research Group. He works in the area of evaluating of material properties, material failures, analysis and quantification of production factors' influence in production of thin steel sheet stamping parts, modelling and simulation of technological processes, mainly forming processes. He is the author of 5 monographs and more than 350 publications in journals and conference proceedings in Slovakia and abroad. His published works were cited more than 100 times. He has been involved in 60 grant projects, research tasks and 50 projects implemented in industries.

Luboš Kaščák, doc. Ing. PhD., (born in 1974) is an associate professor at the Institute of Technologies and Management, Faculty of Mechanical Engineering, Technical University of Košice. He graduated from the Faculty of Mechanical engineering in 1999. He works in the area of evaluation of properties of joined steel sheets, focusing on resistance spot welding and mechanical joining. He is the author of 2 monographs and more than 100 publications in journals and conference proceedings in Slovakia and abroad. He has been involved in several grant projects and research tasks.

Ján Viňáš, doc. Ing. PhD., IWE., (born in 1977) is an associate professor at the Institute of Technologies and Management, Faculty of Mechanical Engineering, Technical University of Košice. He graduated from the Faculty of Mechanical engineering in 2000. He works in the area of processes of welding, welding-on and soldering, area of material engineering and weldability. He is a member of Slovak Welding Society. He is certified European Welding Engineer and Welding Technologist. He is the author of university textbooks and more than 100 publications in journals and conference proceedings in Slovakia and abroad. He has been involved in several grant projects and research tasks. 